Rev. Bras. Saúde Prod. Anim., Salvador, v.13, n.1, p.74-82 jan/mar, 2012 http://www.rbspa.ufba.br ISSN 15199940

\title{
Complexo homeopático na prevenção e tratamento de diarréias em leitões lactentes
}

\section{Homeopathic complex in the prevention and treatment of diarrhea in suckling piglets}

\author{
KIEFER, Charles ${ }^{1 *}$; RIZZARDI, Rafaela ${ }^{2}$; OLIVEIRA, Bruna Ferreira de ${ }^{3}$; SILVA, \\ Camilla Mendonça ${ }^{4}$; MARTINS, Leandro Pereira ${ }^{4}$; FANTINI, Caiki Calepso ${ }^{4}$
}

\author{
${ }^{1}$ Universidade Federal de Mato Grosso do Sul, Faculdade de Medicina Veterinária e Zootecnia, \\ Departamento de Zootecnia, Campo Grande, Mato Grosso do Sul, Brasil. \\ ${ }^{2}$ Departamento Técnico Real \& Cia Ltda. \\ ${ }^{3}$ Universidade Federal de Mato Grosso do Sul, Programa de Pós-Graduação em Ciência Animal, Campo \\ Grande, Mato Grosso do Sul, Brasil. \\ ${ }^{4}$ Universidade Federal de Mato Grosso do Sul, Faculdade de Medicina Veterinária, Campo Grande, Mato \\ Grosso do Sul, Brasil. \\ *Endereço para correspondência: charles.kiefer@ufms.br
}

\section{RESUMO}

O trabalho foi realizado com o objetivo de comparar o potencial do antibiótico e de um complexo homeopático sobre a prevenção e tratamento de diarréia em leitões lactentes, bem como comparar e avaliar os resultados de desempenho e mortalidade durante a fase de aleitamento. Foram utilizadas 98 leitegadas, em um total de 988 leitões, de matrizes com ordem média de 5,92 $\pm 2,65$ partos. As leitegadas foram distribuídas em delineamento experimental de blocos ao acaso, composto pelos tratamentos controle, antibiótico e complexo homeopático. Adotou-se a ordem de parto das matrizes como critério de bloqueamento. No segundo dia de vida, as leitegadas foram submetidas à pesagem e aplicação, por via oral, de $2,0 \mathrm{~mL}$ do antibiótico colistina ou $4,0 \mathrm{~mL}$ de complexo homeopático por leitão. As leitegadas foram desmamadas com idade média de $22,97 \pm 2,43$ dias. Não houve efeito dos tratamentos sobre o desempenho e a mortalidade dos leitões. Foi constatada diferença quanto ao percentual de eficiência no tratamento de diarréia, o complexo homeopático apresentou eficiência superior em relação ao antibiótico (95,2\% versus 90,0\%). Concluiu-se que o complexo homeopático foi eficiente na prevenção e tratamento das diarréias dos leitões lactentes, e pode ser utilizado em substituição aos antibióticos.

\section{SUMMARY}

The aim of this study was compare the potential of an antibiotic and homeopathic complex on the prevention and treatment of diarrhea in suckling piglets and to compare and evaluate the performance results and mortality during the lactation. Ninety eight litters, totaling 988 piglets, from females with reproductive cycles order of $5.92 \pm 2.65$. The litters were allotted to a randomized block experiment consisting of the control, antibiotic and homeopathic complex treatments. It was adopted the reproductive cycle order of the females as blocking criteria. On the second day of life, litters were weighed and submitted to oral application of $2.0 \mathrm{~mL}$ colistin antibiotic or $4.0 \mathrm{~mL}$ of homeopathic complex per piglet. The piglets were weaned at an average age of $22.97 \pm 2.43$ days. No effect of treatments on performance and mortality of piglets was noted. Difference was found in the percentage of efficiency in the treatment of diarrhea, and the homeopathic complex showed superior efficiency in relation to the antibiotic $(95.2 \%$ versus $90.0 \%)$. It was concluded that the homeopathic complex was effective in the prevention and treatment of diarrhea of suckling piglets and may be used as a substitute to the antibiotic.

Keywords: antibiotics, enteritis, homeopathy, swines

Palavras-chave: antibióticos, enterites, homeopatia, suínos 


\section{INTRODUÇÃO}

A utilização excessiva de antibióticos na nutrição animal pode resultar em efeitos negativos sobre a saúde animal, humana e ao meio ambiente (SARMAH et al., 2006). Na Europa, os antibióticos usados como aditivos foram proibidos devido à possibilidade de conferir resistência cruzada a patógenos comuns a animais e humanos (LORA GRAÑA et al., 2010), fato que tem gerado a necessidade do desenvolvimento de substitutos alternativos sustentáveis para a prevenção e tratamento de patologias, tais como os medicamentos homeopáticos (CAMERLINK et al., 2010).

A homeopatia tem sido estudada e utilizada há mais de duas décadas em nosso país, não só de modo curativo como preventivo. Criada em 1796, pelo médico alemão Samuel Hahnemann, a homeopatia se fundamenta na utilização de substâncias medicamentosas diluídas e dinamizadas, previamente experimentadas. Para tal, sua utilização deve obedecer a lei dos semelhantes - Similia Similibus Curantur (PUSTIGLIONE, 2001).

A homeopatia, tal como foi idealizada por Hahnemann é uma terapêutica curativa e individual, fundamentada na semelhança entre a patogenesia do medicamento e a sintomatologia do paciente e na utilização de um só medicamento, em dose mínima (HAHNEMANN, 1980).

Os que usam um único medicamento são denominados "unicistas", os que usam mais de um medicamento em momentos diferentes para o mesmo paciente são os "pluralista", que se dividem em "alternistas", quando é usado um medicamento de cada vez, porém alternado com outros que complementem a sua ação, e os que utilizam vários medicamentos associados, os "complexistas". $\mathrm{Na}$ década de 80, surgiu em Mato Grosso do Sul uma nova corrente homeopática complexista que visa tratar rebanhos, denominada de homeopatia populacional (REAL, 2008). O método consiste em utilizar diferentes medicamentos homeopáticos reunidos em "complexos" que são administrados nos alimentos, suplementos minerais ou na água, o que possibilita a medicação de populações.

Os complexos homeopáticos têm sido administrados como prevenção das enterites e melhorado os índices zootécnicos dos animais. Tem-se constatado que a homeopatia apresenta eficácia na produção de suínos quando associada ao manejo sanitário adequado (SOTO et al., 2007).

Diante da dificuldade de minimizar as perdas econômicas decorrentes de diarréias e melhorar a produtividade, realizou-se este trabalho com o objetivo de avaliar o potencial de substituição dos antibióticos por medicamentos homeopáticos na prevenção e tratamento de diarréias em leitões lactentes.

\section{MATERIAL E MÉTODOS}

O experimento foi realizado na suinocultura Rancho Alegre, localizada no município de Campo Grande/MS. Foram utilizados 988 leitões, oriundos de 98 leitegadas, de matrizes com ordem média de 5,92 $\pm 2,65$ partos. As matrizes e suas leitegadas foram alojadas em três salas de maternidade, cobertas com telhas de fibrocimento, equipadas com celas parideiras com escamoteador. $\mathrm{O}$ piso das celas parideiras das maternidades era vazado e o escamoteador possuía aquecimento regulável para os leitões. As leitegadas foram distribuídas em delineamento experimental de blocos ao 
acaso, composto por três tratamentos (complexo homeopático, fórmula básica: Collibacilinum $10^{-60}$; Mercurius dulcis $10^{-}$ 30; Chinchona officinalis $10^{-60}$; Enterococcinum $10^{-400}$; Podophylum peltaltum $10^{-6}$; Colocynthis $10^{-6}$; antibiótico e controle), com 33 repetições para os tratamentos controle e complexo homeopático e 32 repetições para o tratamento antibiótico, e cada unidade experimental constituída por uma leitegada. Para a formação dos blocos, levou-se em consideração a ordem de parto das fêmeas. Os tratamentos experimentais foram distribuídos uniformemente em três salas de maternidade.

No segundo dia de vida, as leitegadas foram submetidas à equalização a fim de promover a homogeneidade em tamanho corporal e número de leitões. Uma vez realizada a equalização, as leitegadas foram submetidas à pesagem e a aplicação, por via oral, do antibiótico ou do complexo homeopático. $\mathrm{O}$ antibiótico eleito para o tratamento foi a colistina ${ }^{\circledR}$ que foi aplicada na dosagem de $2,0 \mathrm{~mL}$ por leitão e o complexo homeopático na dose de 4,0mL por leitão.

No transcorrer do período experimental foi realizado diariamente, às $8 \mathrm{hs}$ e às 14hs, o monitoramento da ocorrência de diarréias nos leitões, por meio da observação das instalações e de todos os leitões das leitegadas. Também foi avaliado o grau de severidade das diarréias por meio do escore fecal, no qual foram considerados escore 0 para fezes normais, escore 1 para fezes pastosas e o escore 2 para fezes líquidas. Aqueles leitões cujo escorre fecal foi igual a 2 foram considerados como ocorrência de diarréia

Uma vez identificados, os leitões com diarréia foram submetidos à medicação, e os leitões do tratamento com antibiótico foram submetidos à aplicação intramuscular de $1,0 \mathrm{~mL}$ de mogiflox ${ }^{\circledR}$ (enrofloxacino). Os leitões do tratamento com o complexo homeopático foram submetidos à aplicação oral de $4,0 \mathrm{~mL}$ do mesmo produto.

Por sua vez, os leitões com diarréia provenientes do grupo controle foram submetidos ao tratamento com a aplicação intramuscular de $1,0 \mathrm{~mL}$ de mogiflox ${ }^{\circledR}$ (enrofloxacino) ou a aplicação oral de 4,0mL do complexo homeopático, sendo que o estabelecimento da distribuição da medicação foi realizado ao acaso, por ocasião da distribuição das leitegadas no delineamento experimental no início do experimento, com a utilização do mesmo critério de bloqueamento.

Após a medicação dos leitões com diarréia, os mesmos foram marcados para verificação da reincidência de diarréia no dia seguinte à medicação, para avaliar a eficiência do tratamento utilizado e a necessidade de repetição do tratamento.

No transcorrer do experimento todos os leitões foram submetidos aos manejos convencionais da maternidade, como a aplicação de ferro dextrano e de coccidicida por ocasião do terceiro dia, castração dos machos e vacinação contra Mycoplasma spp. ao sétimo dia de vida. A partir do sétimo dia até o dia da desmama foi fornecida ração préinicial especial a todas as leitegadas.

Durante o período experimental, a temperatura e a umidade relativa do ambiente foram monitoradas diariamente às $7 \mathrm{hs}, 13 \mathrm{hs}$ e $18 \mathrm{hs}$, por meio de um conjunto de termômetros de bulbo seco e bulbo úmido e de globo negro que foram instalados no centro da maternidade. Os valores registrados foram, posteriormente, convertidos no índice de temperatura de globo e umidade (ITGU), o que caracterizou o 
ambiente térmico em que os animais foram mantidos.

O período experimental teve duração total de 27 dias, e as leitegadas foram desmamadas com idade média de $23,0 \pm 2,43$ dias. Ao final do período experimental (ocasião da desmama), todas as leitegadas foram pesadas para a determinação do peso de desmame e a determinação do ganho de peso dos leitões e leitegadas.

As variáveis avaliadas foram o peso inicial e final dos leitões, o peso inicial e final das leitegadas, o ganho de peso dos leitões e das leitegadas, o número de leitões desmamados por leitegada, a mortalidade dos leitões, a incidência de diarréia, o escore fecal e a eficiência da medicação no tratamento das diarréias.

Os dados de desempenho foram tabulados e submetidos à análise de variância por intermédio do procedimento GLM e, posteriormente, teste Student NewmanKeuls para comparação de médias. Os dados de ocorrência de diarréia foram submetidos à análise de frequência pelo procedimento "Freq" e os escores de diarréia foram submetidos à análise de Wilcoxon. As análises estatísticas foram realizadas com utilização do programa estatístico SAS (SAS INSTITUTE, 2001), ao nível de 5\% de significância.

\section{RESULTADOS E DISCUSSÃO}

Durante o período experimental, a temperatura média do ar registrada no interior das salas da maternidade foi de $27,7 \pm 2,8^{\circ} \mathrm{C}$, a umidade relativa foi $87,1 \pm 9,7 \%$ e a temperatura de globo negro foi $27,8 \pm 2,8^{\circ} \mathrm{C}$.

A temperatura média do ar obtida neste estudo caracteriza o ambiente térmico como um ambiente de estresse por calor, uma vez que a temperatura média do ar está acima da faixa de temperaturas entre 18 e $23^{\circ} \mathrm{C}$, considerada ideal para esta categoria animal (BROWN-BRANDL et al., 2001).

O ITGU calculado durante o período experimental foi de 78,1 $\pm 3,2$. Segundo Campos et al. (2008), valores de ITGU superiores a 72,0 elevam a frequência respiratória e a temperatura retal de matrizes suínas em lactação e evidenciam a ocorrência de desconforto e estresse térmico. Além disso, segundo esses pesquisadores, valores elevados de ITGU podem prejudicar o consumo de alimento, a produção de leite e o ganho de peso dos leitões e das leitegadas. Portanto, o ITGU calculado no transcorrer deste trabalho caracteriza o ambiente térmico ambiental como de estresse por calor.

A ordem média de partos das fêmeas utilizadas no estudo foi de 6,22; 5,68 e 5,84 para os tratamentos controle, antibiótico e homeopatia, respectivamente (Tabela 1). A duração do período de lactação não diferiu $(\mathrm{P}>0,05)$ entre os tratamentos, e a duração média do período de lactação do presente estudo foi de $22,97 \pm 2,43$ dias.

Não foram observados efeitos $(\mathrm{P}>0,05)$ dos tratamentos sobre o número de leitões desmamados, peso dos leitões e das leitegadas ao desmame, bem como sobre o ganho de peso dos leitões e das leitegadas no transcorrer do período de lactação. Os tratamentos experimentais também não influenciaram $(\mathrm{P}>0,05)$ a mortalidade dos leitões.

Embora não se tenha constatado diferença estatística para o ganho de peso dos leitões no transcorrer do período experimental neste estudo, pesquisas têm constatado que a incidência elevada de diarréia pode causar uma redução de até oito gramas no ganho de peso diário dos leitões do nascimento ao desmame (JOHANSEN et al., 2004). 
Rev. Bras. Saúde Prod. Anim., Salvador, v.13, n.1, p.74-82 jan/mar, 2012 http://www.rbspa.ufba.br ISSN 15199940

Tabela 1. Desempenho dos leitões e leitegadas em sala com alto desafio sanitário

\begin{tabular}{|c|c|c|c|c|c|c|}
\hline \multirow{2}{*}{ Variáveis } & \multicolumn{3}{|c|}{ Tratamentos } & \multirow{2}{*}{ Média } & \multirow{2}{*}{$\mathrm{P}<$} & \multirow{2}{*}{$\begin{array}{l}\text { CV } \\
(\%)\end{array}$} \\
\hline & Controle & Antibiótico & Homeopatia & & & \\
\hline Matrizes $\left(n^{o}\right)$ & 33 & 32 & 33 & - & - & - \\
\hline Ordem de partos & 6,22 & 5,68 & 5,84 & 5,92 & - & - \\
\hline Lactação (dias) & 22,91 & 22,91 & 22,91 & 22,91 & - & - \\
\hline \multicolumn{7}{|c|}{ Número de leitões } \\
\hline Inicial & 10,28 & 10,06 & 10,21 & 10,19 & 0,37 & 42,94 \\
\hline Ao desmame & 9,33 & 9,28 & 9,27 & 9,30 & 0,98 & 17,87 \\
\hline Mortalidade $\left(\mathrm{n}^{\circ}\right)$ & 0,95 & 0,78 & 0,94 & 0,89 & 0,40 & 11,41 \\
\hline \multicolumn{7}{|c|}{ Peso dos leitões } \\
\hline Inicial (kg) & 1,62 & 1,62 & 1,70 & 1,65 & 0,66 & 25,39 \\
\hline Ao desmame (kg) & 6,40 & 6,62 & 6,40 & 6,45 & 0,70 & 18,76 \\
\hline \multicolumn{7}{|c|}{ Peso da leitegada } \\
\hline Inicial (kg) & 16,75 & 16,23 & 17,29 & 16,76 & 0,63 & 26,60 \\
\hline Ao desmame (kg) & 60,27 & 61,73 & 59,95 & 60,47 & 0,89 & 27,29 \\
\hline \multicolumn{7}{|c|}{ Ganho de peso } \\
\hline Leitão (kg) & 4,83 & 5,00 & 4,70 & 4,85 & 0,71 & 32,34 \\
\hline Leitegada (kg) & 43,65 & 45,51 & 42,66 & 43,93 & 0,70 & 31,34 \\
\hline Leitão (g/dia) & 212 & 219 & 205 & 212 & 0,51 & 21,76 \\
\hline Leitegada (kg/dia) & 1,92 & 1,99 & 1,87 & 1,93 & 0,44 & 19,90 \\
\hline
\end{tabular}

Médias entre os tratamentos não diferem entre si, ao nível de 5\% de significância.

Verificou-se maior $(\mathrm{P}<0,05)$ ocorrência total e percentual de diarréias nas leitegadas do grupo controle em relação ao grupo submetido ao complexo homeopático, que por sua vez apresentaram maior $(\mathrm{P}<0,05)$ ocorrência total e percentual de diarréias em relação ao grupo submetido à aplicação de antibióticos (Tabela 2, Figura 1). Contudo, não foi constatado efeito $(\mathrm{P}>0,05)$ dos tratamentos sobre o escore fecal dos leitões.

Os resultados dessa pesquisa são corroborados por Camerlink et al. (2010), que também verificaram redução significativa da ocorrência de diarréias em leitões após o nascimento quando submetidos ao medicamento homeopático comparados aos leitões que receberam placebo. Os mesmos pesquisadores verificaram que houve tendência de maior duração da diarréia nos leitões que receberam placebo e, além disso, $54 \%$ dos leitões que receberam placebo apresentaram uma taxa de morbidade $0,20 \%$ superior. Esses autores concluíram que a homeopatia oferece uma boa proteção contra a diarréia.

Ao se considerar que a ocorrência total e percentual de diarréias foram inferiores nos grupos tratados com antibiótico e complexo homeopático em relação ao grupo controle, pode-se inferir que o manejo de aplicação dos medicamentos, no segundo dia de vida, pode ser uma medida eficaz como ação preventiva à incidência de diarréias nos leitões. 
Rev. Bras. Saúde Prod. Anim., Salvador, v.13, n.1, p.74-82 jan/mar, 2012 http://www.rbspa.ufba.br ISSN 15199940

Tabela 2. Ocorrência de diarréias e escore fecal

\begin{tabular}{|c|c|c|c|c|c|}
\hline \multirow{2}{*}{ Variáveis } & \multicolumn{3}{|c|}{ Tratamentos } & \multirow{2}{*}{ Média } & \multirow{2}{*}{$\mathrm{P}<$} \\
\hline & Controle & Antibiótico & Homeopatia & & \\
\hline $\begin{array}{l}\text { Ocorrência de diarréias } \\
\text { (nº leitões) }\end{array}$ & $159^{\mathrm{a}}$ & $96^{\mathrm{c}}$ & $135^{b}$ & 130 & 0,05 \\
\hline Ocorrência de diarréias (\%) & $40,77^{\mathrm{a}}$ & $24,62^{\mathrm{c}}$ & $34,62^{\mathrm{b}}$ & 33,33 & 0,05 \\
\hline Escore fecal & 1,31 & 1,33 & 1,33 & 1,32 & 0,94 \\
\hline
\end{tabular}

Médias nas linhas seguidas por letras diferentes diferem entre si ao nível de 5\% de significância.

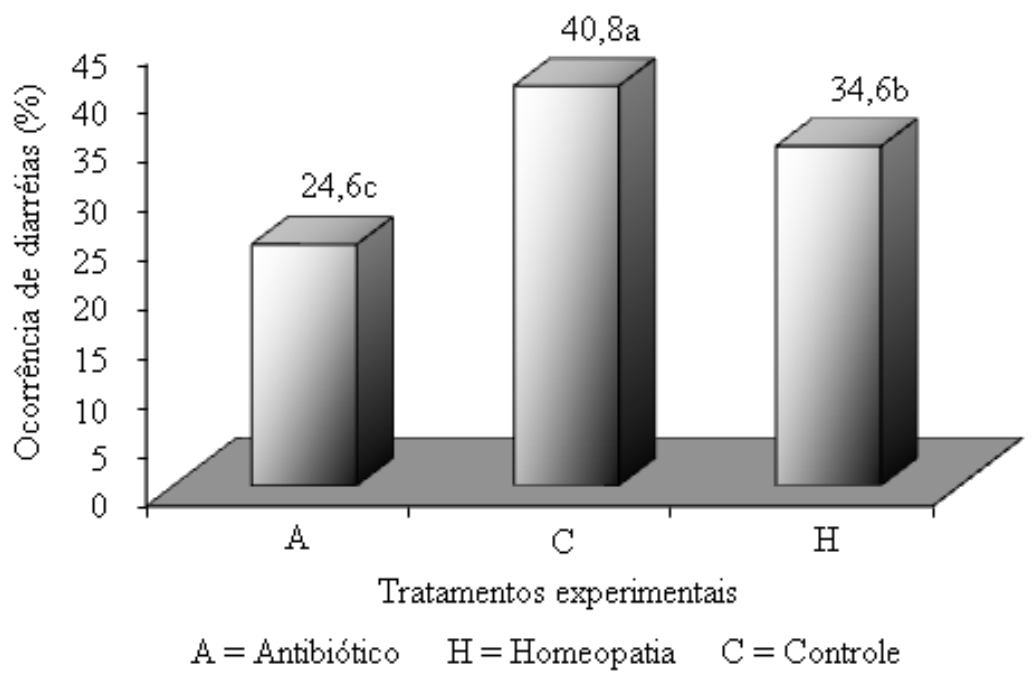

Figura 1. Ocorrência percentual total de diarréias nas leitegadas no período de lactação

Pode-se observar que o resultado de incidência média diária de diarréias nos leitões (Figura 2) está em consonância com os observados para a ocorrência total de diarréias, ou seja, leitões do grupo controle apresentaram maior $(\mathrm{P}<0,05)$ incidência diária de diarréias em relação ao tratamento com o complexo homeopático, que por sua vez apresentaram maior $(\mathrm{P}<0,05)$ incidência quando comparados ao grupo antibiótico.

Foi constatado efeito $(\mathrm{P}<0,05)$ dos tratamentos sobre a eficiência percentual do tratamento das diarréias ao se utilizar o antibiótico e o complexo homeopático. Entretanto, o produto homeopático possibilitou eficiência superior $(\mathrm{P}<0,05)$ em relação ao antibiótico $(95,2$ versus $90,0 \%)$ por ocasião da primeira aplicação do produto (Figura 3). Por sua vez, a eficiência percentual dos tratamentos por ocasião da segunda aplicação dos medicamentos em função da reincidência de diarréia foi de $100 \%$ em ambos medicamentos.

Embora já utilizados por muitas décadas, os tratamentos homeopáticos ainda não apresentam uma explanação científica para o seu mecanismo de ação (CUCHERAT et al., 2000). Esses mesmos pesquisadores realizaram um estudo meta-analítico e concluíram que 
Rev. Bras. Saúde Prod. Anim., Salvador, v.13, n.1, p.74-82 jan/mar, 2012 http://www.rbspa.ufba.br ISSN 15199940

não há evidências suficientes para afirmar que a homeopatia seja clinicamente eficiente. Contudo, enfatizaram que a homeopatia deve ser avaliada segundo a mesma metodologia empregada para a alopatia.

Por outro lado, alguns estudos têm constatado bons resultados quanto à aplicação da homeopatia, como o trabalho de Coelho et al. (2009), que demonstrou que o tratamento homeopático foi mais eficiente que o tratamento com antibióticos no controle da diarréia em leitões recém nascidos, e concluiu que a homeopatia é uma alternativa efetiva no tratamento da diarréia causada por Escherichia coli em leitões.

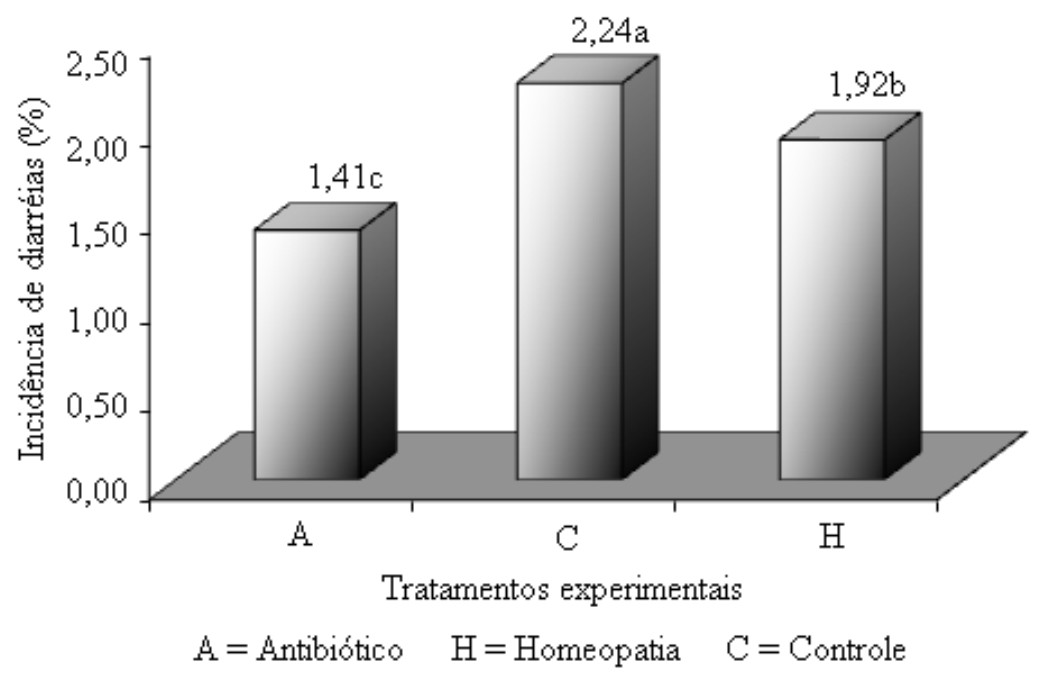

Figura 2. Incidência média diária de diarréias

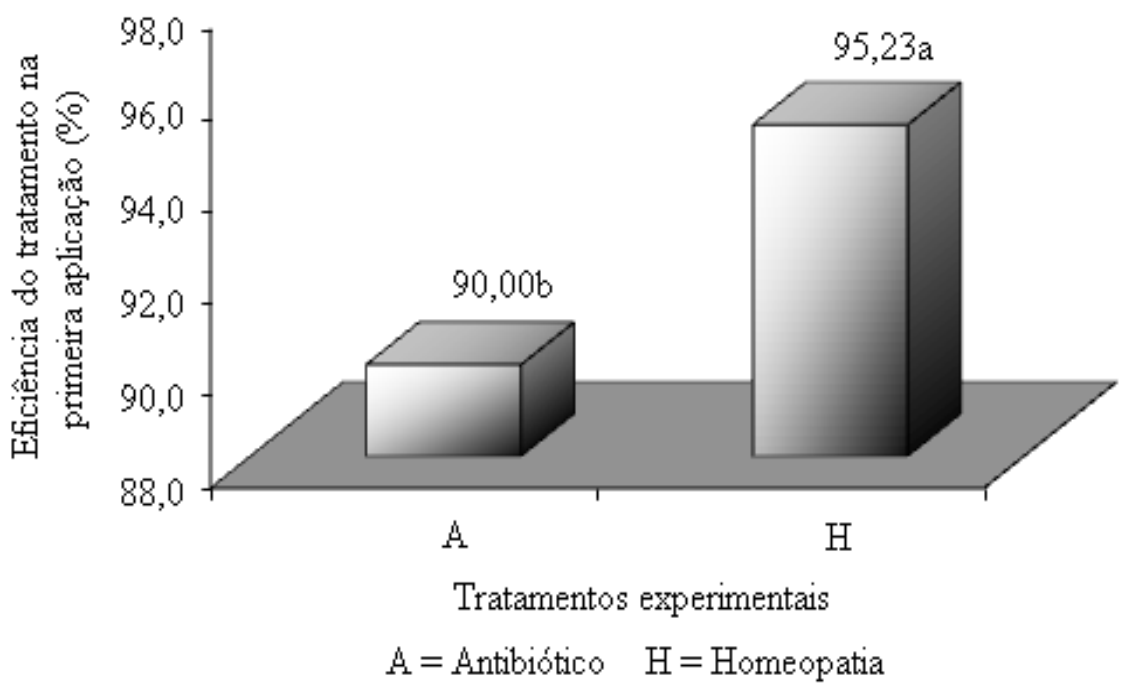

Figura 3. Eficiência percentual do antibiótico e do medicamento homeopático no tratamento de diarréias na primeira aplicação 
Rev. Bras. Saúde Prod. Anim., Salvador, v.13, n.1, p.74-82 jan/mar, 2012 http://www.rbspa.ufba.br ISSN 15199940

Outros trabalhos também evidenciam efeitos positivos da homeopatia, como o de Soto et al. (2008) no qual obteve-se redução da mortalidade dos leitões de 5,9 para $0,3 \%$ a partir da utilização da homeopatia. Albrecht \& Schütte (1999) constataram superioridade dos resultados dos suínos submetidos ao tratamento homeopático quando comparados ao grupo tratado com antibióticos. Também em aves, a terapia com a homeopatia diminuiu a excreção de Salmonella enteritidis em poedeiras comerciais, o que reduziu a contaminação dos ovos na cloaca (BERCHIERI JÚNIOR et al., 2006). Além disso, devese destacar que a homeopatia poderá contribuir no combate ao desenvolvimento da resistência dos micro-organismos aos antibióticos (VIKSVEEN, 2003).

Concluiu-se que a utilização do antibiótico colistina e o complexo homeopático foram efetivos para a prevenção de diarréias em leitões lactentes. O complexo homeopático foi eficiente no tratamento das diarréias dos leitões lactentes e pode ser utilizado como substituto dos antibióticos.

\section{AGRADECIMENTOS}

Os autores agradecem a Real $H$ e aos proprietários da suinocultura Rancho Alegre pelo apoio na realização desta pesquisa.

\section{REFERÊNCIAS}

ALBRECHT, H.; SCHÜTTE, A. Homeopathy versus antibiotics in metaphylaxis of infectious diseases: a clinical study in pig fattening and its significance to consumers. Alternative Therapies in Health and Medicine, v.5, p.64-68, 1999.
BERCHIERI JÚNIOR, A.; TURCO, W.C.P.; PAIVA, J.B.; OLIVEIRA, G.H.; STERZO, EV. Evaluation of isopathic treatment of Salmonella enteritidis in poultry. Homeopathy, v.95, p.94-97, 2006.

BROWN-BRANDL, T.M.; EIGENGERG, R.A.; NIENABER, J.A.; KACHMAN, S.D.

Thermoregulatory profile of a newer genetic line of pigs. Livestock

Production Science, v.71, p.253-260, 2001.

CAMERLINK, I.; ELLINGER, L.; BAKKER, E.J.; LANTINGA, E.A. Homeopathy as replacement to antibiotics in the case of Escherichia coli diarrhea in neonatal piglets. Homeopathy, v.99, p.57-62, 2010.

CAMPOS, J.A.; TINÔCO, I.F.F.; BAÊTA, F.C.; SILVA, J.N.; CARVALHO, C.S.; MAUIRI, A.L. Ambiente térmico e desempenho de suínos em dois modelos de maternidade e creche. Revista

CERES, v.55, p.187-193, 2008.

COELHO, C.P.; SOTO, F.R.M.; VUADEN, E.R.; MELVILLE, P.A.; OLIVEIRA, F.C.S.; BENITES, N.R. Evaluation of preventive homeopathic treatment against Colibacillosis in swine production. International Journal of High Dilution Research, v.8, p.183-190, 2009.

CUCHERAT, M.; HAUGH, M.C.; GOOCH, M.; BOISSEL, J.P.

Evidence of clinical eficacy of homeopathy - A meta-analysis of clinical trials. European Journal of Clinical Pharmacology, v.56, p.2733, 2000. 
Rev. Bras. Saúde Prod. Anim., Salvador, v.13, n.1, p.74-82 jan/mar, 2012 http://www.rbspa.ufba.br ISSN 15199940

LORA GRAÑA, G.; FERREIRA, A.S.; SILVA, F.C.O.; LORA GRAÑA, A.; ARAÚJO, W.A.G.; PEREIRA, C.M.C. Plasma sanguíneo em dietas sem antibióticos para leitões desmamados aos 21 dias de idade. Revista Brasileira de Saúde e Produção Animal [online], v.11, p.815-826, 2010.

HAHNEMANN, S. Organon da arte de curar. São Paulo: Robe Editorial, 1980. 248p.

JOHANSEN, M.; ALBAN, L.; KJAERSGÃRD, H.; BAEKBO, P. Factors associated with suckling piglet average daily gain. Preventive

Veterinary Medicine, v.63, p.91-102, 2004.

\section{PUSTIGLIONE, M. (O moderno)} Organon da Arte de Curar de Samuel Hahnemann. São Paulo: Typus, 2001. 320 p.

REAL, C.M. Homeopatia populacional. Fundamento. Ruptura de um Paradigma. A Hora Veterinária, n.165, p.30-37, 2008.

SARMAH, A.K.; MEYER, M.T.; BOXALL, A.B.A. A global perspective on the use, sales, exposure pathways, occurrence, fate and effects of veterinary antibiotics (VAs) in the environment. Chemosphere, v.65, p.725-759, 2006.
SAS INSTITUTE. User's guide.

Version 6. 4.ed. North Caroline, 2001, 1686p.

SOTO, F.R.M.; VUADEN, E.R.; BENITES, N.R.; AZEVEDO, S.S.; PINHEIRO, S.R.; COELHO, C.P.; VASCONCELLOS, S.A. Avaliação dos índices zootécnicos de uma granja comercial com a utilização do tratamento homeopático. Veterinária e Zootecnia, v.15, p.100-115, 2008.

SOTO, F.R.M.; VUADEN, E.R.; BENITES, N.R.; AZEVEDO, S.S.; PINHEIRO, S.R.; BERNARDI, F.; COELHO, C.P.; VASCONCELLOS, S.A. Implantação da homeopatia e avaliação dos índices de mortalidade de uma granja comercial de suínos comparado com a alopatia nas fases de creche, recria e terminação. Veterinária e Zootecnia, v.14, p.107-114, 2007.

VIKSVEEN, P. Antibiotics and the development of resistant microorganisms. Can homeopathy be an alternative? Homeopathy, v.92, p.99107, 2003.

Data de recebimento: $28 / 03 / 2011$

Data de aprovação: 09/12/2011 